\title{
ESPAÑOLISMO Y CATALANIDAD EN LA HISTORIOGRAFÍA CATALANA DECIMONÓNICA*
}

por

\section{Pere ANGUera}

Universitat Rovira i Virgili

RESUMEN: Los plateamientos bistoriográficos modernos surgieron en las primeras décadas del siglo XIX de manera paralela a la aparición de los nacionalismos. En un primer momento la bistoriografía catalana respondió a la demanda social de un sector que no habia olvidado los componentes de comunidad diferenciada, para dar paso a diversos estudios que proponian identificar las viejas libertades con las emanadas del constiucionalismo liberal para hacerlas más atractivas. La inarticulación de Espa$\tilde{n} a$, reconocida desde círculos próximos al poder facilitaba el orgullo territorial. Las primeras historias generales querían evitar la identificación, en el pasado y en su presente, de Castilla con España, en la doble voluntad de contribuir a una historia estatal más plural y de defender una estructura más o menos federalizante. A finales de siglo, la implantación del catalanismo, impulsó una nueva bistoriografía centrada exclusivamente en Cataluña. Los materiales aportados por los bistoriadores fueron aprovechados en todo tipo de discursos, que a su vez los reinterpretaban. Aquí se ofrece una aproximación a los pronunciados en los Jocs Florals, la más importante plataforma cultural de la Renaixença.

PALABRAS Clave: Historiografía. Nacionalismo. Cataluña.

ABSTRACT: The modern historiographic raisings had arisen in the first decades of the XIXth century on a parallel way to the appearance of the nationalisms. In a first instance, The Catalan bistoriography replied to the social request of a sector which had not forgotten the components if differenciate community, in order to make known several studies which proposed the identification of the old liberties with the ones originated in the liberal consdtitutionalism to make them more attractive. The desarticulation of Spain, recognised from circles close to power made easy the territorial pride. The first general histories would avoid the identification in the past and in its present of

\footnotetext{
* Este artículo se incribe en el proyecto de investigación PB97-0404.
} 
Castilia as Spain, in a double will to contribute to an state more plural and to defend an structure more or less federalist. At the end of the century, the implantation of catalanism bad urged a new bistoriography exclusively centred in Catalonia. The materials furnished by historian were used in every kind of speeches, which at the same time reinterpreted them. Here is offered an approach to those pronounced in the Floral Games, the most important cultural platform of the Renaissance.

KEY WORDS: Historiography. Nationalism. Cataluña.

\section{EL RESURGIR DE LA HISTORIOGRAFÍA CATALANA}

Las primeras manifestaciones de reivindicación historiográfica del pasado catalán con un espíritu vagamente moderno coinciden con la difusión del romanticismo. La constatación no constituye ninguna novedad, como tampoco lo es la afirmación que su coincidencia con la segunda etapa absolutista de Fernando VII limite en gran medida sus posibilidades de expresión, especialmente cuando algunos de sus componentes como el espíritu constitucional y los elogios de la libertad civil chocaban con la realidad política del momento y habían sido auspiciados por el liberalismo durante el Trienio ${ }^{1}$. Ambos motivos incidieron en el hecho que las muestras de catalanidad apenas afloraran en El Europeo, la revista que introdujo el romanticismo en España ${ }^{2}$. Pese a ello, uno de sus redactores, B. C. Aribau, el futuro autor de la «Oda a la pàtria (considerada a menudo como el punto de arranque de la Renaixença) y director de la Biblioteca de Autores Españoles, dedicó unas páginas a describir las Rúbriques de Bruniquer, que aprovechó» para glosar las viejas glorias de Barcelona, cuando «la celebridad de sus instituciones y la firmeza de sus magistrados la hicieron intervenir poderosamente en los negocios generales de la Europa». Aribau recomendaba dedicar los ocios a la investigación para «considerar lo que fuimos algún día» mientras elogiaba "los debates que sostuvieron nuestros mayores por violación de privilegios, libertades, prácticas y costumbres antiguas de la ciudad, «ó del Principado», que terminaban siempre con el triunfo de la justicia, poniendo en evidencia «la enorme preponderancia del pueblo catalán cuando trataba de conservar sus derechos» ${ }^{3}$.

\footnotetext{
1 Para el contexto ideológico en Cataluña y en especial para situar las producciones historiográficas en las reivindicaciones políticas catalanistas remito a ANGUERA, Pere: Els precedents del catalanisme. Catalanitat $i$ anticentralisme: 1808-1868, Barcelona 2000. Para el Trienio, pp. 88-105.

2 Véase por ejemplo ALLISON PEERs, Edgard: Historia del movimiento romántico español, Madrid 1973, pp. 163-168. Para la sensibilidad histórica catalana de la revista SoDEVILA, Ferran: Histùria de Catalunya, Barcelona 1963, pp. 1313-1315.

3 A[RIBAU], "Historia. Noticia de la obra inedita conocida por el nombre de Rúbrica de Bruniquer, custodiada en el archivo del ayuntamiento de Barcelona", El Europeo, 5 (15-XI-1823), pp. 152-157, las citas en las pp. 152, 153 y 155. Para el impacto de El Europeo en la cultura catalana, 
Los jóvenes redactores de la revista no dieron ninguna otra muestra directa de sensibilidad catalana. Sólo Ramón López Soler hizo unas elucubraciones teóricas sobre el peso de las tradiciones en el sentimiento nacional: «la Religión, el clima, el idioma, las leyes y otras muchas circunstancias hermanan entre sí á los individuos de una nación y les hacen adoptar ciertos usos característicos». Estos usos, continuaba, eran lo único que los exiliados podían llevar consigo. López Soler quería en realidad retratar España, pero le salía Cataluña, que tenía lengua, alguna ley (el código civil que era el de mayor incidencia en la mayoría de la población) y muchas costumbres propias. Seguramente lo que echaban de menos los exiliados catalanes era más el catalán que el castellano, utilizado con dificultad por la mayoría ${ }^{4}$, junto al pesar de no poder dar la mona de Pascua al ahijado, más que cualquiera improbable costumbre compartida con el resto del estado. Como más aplicable a Cataluña, que no a España, resulta la referencia al «melancólico recuerdo" provocado por «un canto nacional», unas añoranzas que no sentía «quién no tuviese patria, y que arrancan lagrimas de ternura á los que en tales ocasiones no pueden menos de acordarse de ella», porqué «canto nacional» no significa aquí himno, sino canción popular ${ }^{5}$. ¿Qué era la patria para López Soler? La respuesta la da el mismo: «esta palabra patria no solamente nos da una idea de las relaciones contraídas en nuestra infancia, de los objetos que inflamaron por la primera vez a nuestra juventud, y de las personas que tienen un derecho a nuestro afecto; sino que nos la da también de aquellas encantadoras costumbres en que fuimos criados», con lo que de nuevo remite a un territorio más limitado y definido que el español. Para López Soler mantener las tradiciones equivalía a conservar la potencia de la patria: «un pueblo ligado con unas mismas costumbres (...) prefiere constantemente la pérdida de la vida a la de los usos (...), este es el pueblo amante de su independencia política, este es el que todo lo sacrifica por defenderla». Es más: «mientras han guardado las primitivas costumbres han amado la verdad y apreciado las sabias leyes» ${ }^{6}$. El autor quería una vez más referirse a España, pero los ejemplos podían empujar a más de un lector a aplicar los comentarios a Cataluña, incluso la denuncia de la unificación de las costumbres y formas de vestir que se producía en Europa, era más fácilmente identificable con la que desde tiempo atrás se daba en España.

\footnotetext{
SARDÀ, Joan: Piferrer, Barcelona 1884, pp. 24-26. En todas las citas mantengo la ortografía del original.

${ }^{4}$ Para la situación lingüística en Cataluña a lo largo del siglo XIX remito a ANGUERA, Pere: El català al segle XIX. De llengua del poble a llengua nacional, Barcelona 1997.

5 No existía en aquel momento ningún «himno nacional», cfra. SERRANO, Carlos: El nacimiento de Carmen. Símbolos, mitos y nación, Madrid 1999, esp. pp. 111-115, y resulta impensable que en plena Década Ominosa López Soler se refiriese a un himno político como el de Riego, que sí podía despertar emotivos recuerdos entre los emigrados políticos.

' L[OPEZ] S[OLER], «Política. Perjuicios que acarrea el olvido de las costumbres nacionales», El Europeo, 4, (31-I-1824), pp. 109-118. Para las citas, pp. 110-111 y 113.
} 
La falta de interés de El Europeo en divulgar la propia historia contrasta con el afán de recuperación promovido por Fèlix Torres Amat, Albert Pujol y Pròsper de Bofarull, afán que les impulsó a preparar la edición de la Crónica de J. Pujades, en su mayor parte inédita, publicada en ocho volúmenes entre 1829 y 1832. Aquí interesa saber el porqué de esta edición. La principal motivación radicaba en la amplia demanda de una historia general entre los sectores cultos, generada por el amor al país. El valenciano Jaime Villanueva afirmaba en 1821: «no hay en Cataluña Biblioteca grande ni pequeña donde no se halle un ejemplar de la obra titulada Marca Hispánica» de Pedro de Marca, "comprada por los catalanes, por no hallar otra cosa en que se cebe su afición a la antigüedad», por lo que proponía como ineludible la edición de la parte inédita de la crónica de Pujades ${ }^{7}$. La pasión historiográfica justificaba la publicación, favorecida por la difusión del espíritu romántico, con sus componentes de elegíaca exaltación del pasado medieval. Torres, Pujol y Bofarull se proponían imprimir a continuación el dietario de Jaume Ramon Vidal y las Rúbriques de Esteve Gil Bruniquer, entre otros manuscritos, para facilitar así «los medios para escribir la historia de esta porción tan importante de España, principal fin que les movió á la publicación de la Crónica de Pujades» ${ }^{8}$, utilizando un argumento, dar a conocer las glorias catalanas como parte ineludible de las españolas, que reaparecerá en Víctor Balaguer y Antoni de Bofarull. La primera guerra carlista truncó el proyecto nacido con buen pie, ya que fueron «en gran número» los compradores?.

El quinto y sexto volúmenes de la Crónica, los primeros publicados, incluyen la lista de los 462 «señores suscritores», ocho de ellos con dos ejemplares, uno con cuatro, uno con tres y otro, el duque de Medinaceli, con seis. ¿Quiénes eran los interesados en facilitar la recuperación de la historia catalana? El grupo más numeroso lo integran los eclesiásticos: 121 entre individuales y colectivos (38 canónigos, 36 capellanes, 28 frailes, 11 conventos, 5 cabildos y 3 obispos). Le seguían 34 abogados, a los que podrían sumarse los 11 doctores y 5 notarios, en total 50. A continuación venían 24 nobles con título, 11 militares y 9 que hoy en día calificaríamos como altos funcionarios. Deben añadirse dos ayuntamientos, los de Reus y Tarragona, y dos mujeres. En definitiva, junto a algún hacendado y un par de comerciantes, reflejan la estructura de la elite del Antiguo Régimen, aunque esta deducción da poca luz para conocer su realidad social porque, en primer lugar, de más de la mitad de los suscriptores no consta

7 VillanueVa, Jaime: Viaje literario á las iglesias de España, VII, València 1821, p. 233.

8 Crónica, V, p. IX. El Vapor, 24-XII-1833,elogió la edición, «no solo como a hijos de este Principado, amantes de sus glorias», sino también «como interesados en la ilustración pública de España» para "que recupere esta nación el destino que le compete entre las de Europa» y anunciaba la publicación del diccionario de escritores catalanes de Torres Amat: «Cataluña la espera con ansia, y de antemano la mira como uno de los más claros e ilustres testimonios de su gloria».

9 BOFARULL, Antonio de: Estudios, sistema gramatical y crestomanía de la lengua catalana, Barcelona 1864, p. 48.

Hispania, LXI/3, núm. 209 (2001) 907-932 
la profesión, aunque la mayoría reciban el tratamiento de don; en segundo lugar porqué de militares o de eclesiásticos, como de nobles o abogados los había de características muy diversas, y en tercer lugar porqué los potentados eran los únicos con capacidad económica para asumir el coste de la suscripción. Todavía es más difícil establecer la adscripción ideológica mayoritaría ${ }^{10}$, cuyo conocimiento daría luz sobre la sensiblidad identitaria de liberales y absolutistas. De nuevo el problema radica en la imposibilidad de identificar a la mayoría de los que figuran en la lista, aunque la misma falta de relevancia pueda indicar que el interés por el pasado particular era compartido por un amplio sector de las capas cultas. Entre los suscriptores de trayectoria liberal, en un sentido amplio, aparecen el futuro agitador Tomàs Bertran y Soler, B. C. Aribau, el director del tesoro Gaspar de Remisa, Juan Cortada y Ramón Muns y entre los militares Pedro Nolasco Bassa (la víctima de la bullanga de 1835), Antonio Niubó (destacado jefe isabelino) y el camaleónico Francisco Javier Castaños. Más notable parece la presencia de gente proclive al absolutismo con el marqués de Almenara Alta o el conde de Villemur, pasando por parte de la futura plana mayor del carlismo catalán (Bartolomé Torrebadella, Vicente Pou, Fernando de Sagarra), el futuro obispo José Caixal o el ya arzobispo Echanove.

En los años treinta el interés por conocer la historia y los usos políticos catalanes anteriores al decreto de Nueva Planta, se vio favorecido por la necesidad del liberalismo de presentar las libertades constitucionales como herederas de las tradicionales. Así se explica la publicación del libro Constitución catalana y Cortes de Cataluña en noviembre de 1835, aunque también puede ser que la preexistencia de su mitificación generase la operación editorial ${ }^{11}$. Según la propaganda se trataba de una «colección de las antiguas constituciones, prerrogativas, fueros y privilegios de que disfrutó el Principado de Cataluña en unos tiempos en que lo restante de Europa gemía bajo el peso de la odiosa esclavitud». El libro demostraba que Cataluña se había regido con los «elementos de la más democrática libertad, en medio de una bien cimentada monarquía», y era útil «no sólo a nuestros representantes en cortes, sino también a toda suerte de lectores, haciéndoles ver que ha habido en España un país que se ha gobernado dilatados siglos por un régimen constitucional sumamente libre y que debió a ello su mayor felicidad y gloria» ${ }^{12}$. En 1836 se publicó Rasgos verdaderamente sublimes del liberalismo heroico de los antiguos catalanes, para demostrar su

10 Constan dos suscripciones vinculadas a la familia reial, el infante Francisco de Paula, considerado liberal, que encabeza la lista, y con dos ejemplares el bibliotecario real.

11 Para la persistente defensa del modelo «federal» de la España de los Austrias frente al uniformismo borbónico, LLUCH, Ernest: La Catalunya vençuda del segle XVIII. Foscors $i$ clarors de la Il. lustració, Barcelona 1996.

12 Diario de Barcelona, 28-XI-1835. Para las muestras y reivindicaciones de identidad catalana durante la primera guerra carlista ANGUERA: Els precedents, pp. 122-195.

Hispania, LXI/3, núm. 209 (2001) 907-932 
tradición liberal y la de sus instituciones ${ }^{13}$. El Diario de Barcelona, el 28 de marzo de 1837 , anunciaba que se hallaba a la venta Historia de los victoriosísimos condes antiguos de Barcelona. Estas ediciones podían responder, junto a la ya citada voluntad propagandística liberal, a la existencia de un interés que ahora se cafificaría de patriótico. En la misma línea, en junio de 1836, Ramón Muns sugirió a la Academia de Buenas Letras publicar una historia de Cataluña «para la instrucción de la juventud», que se utilizaría en las escuelas, para promover «los sentimientos de rectitud (...), grandeza de alma y amor a la independencia y a una libertad justa, de que estuvieron presididos y de que dieron tan brillantes y repetidos ejemplos nuestros antepasados» ${ }^{14}$. En 1836 el comentario periodístico de La beredera de Sangumi, calificada de «romance original del siglo XII», de J. Cortada, describía así la voluntad del autor: «escitar en la moderna Cataluña el recuerdo de sus antiguas grandezas, rejuvenecer las glorias de los Berengueres» con un predecible paralelismo: «cuando el espíritu guerrero parece renacer en este país y los hijos de la patria corren enardecidos a las armas, no habrá catalán que no nos agradezca el trabajo de presentarle modelos de valor (...) de nuestros heroicos ascendientes» ${ }^{15}$. El mismo Cortada, dos años más tarde, reivindicaba «la historia y (...) las glorias de Cataluña, que por haber pasado en distintas épocas á país estranjero, son por desgracia ignoradas en el nuestro» ${ }^{16}$.

El auténtico resurgir historiográfico lo iniciaron dos obras publicadas en 1836. Las Memorias para ayudar a formar un diccionario crítico de los escritores catalanes, editadas por Fèlix Torres Amat, aprovechando el material acumulado durante años por iniciativa de su tío, el obispo Amat, y Los condes de Barcelona vindicados de Pròsper de Bofarull, que en palabras de Tubino fue «un acontecimiento de entidad en los principios del catalanismo» situando a Bofarull entre los «obreros de la restauración provincial» ${ }^{17}$, opinión compartida por Josep Fontana para quién Los condes son «la primera temptativa de divulgar la história catalana» ${ }^{18}$. Tres años después, los Recuerdos y bellezas de España de Pau Piferrer consolidaban la recuperación. J. Fontana ha podido valorar su trascenden-

\footnotetext{
${ }_{13}$ Un fragmento representativo del opúsculo en CuCurull, Fèlix: Panoràmica del nacionalisme català, II, París 1975, pp. 109-112.

14 Fradera, Josep M.: Cultura nacional en una societat dividida. Patriotisme i cultura a Catalunya (1838-1868), Barcelona 1992, p. 79.

15 «Libros», Diario de Barcelona, 17-II-1836, pp. 387-388.

16 CORTADA, Juan: Las revueltas de Cataluña, ó el Bastardo de Entenza, Barcelona 1838. FrADERA: Cultura, p, 52, considera Cortada el introductor «de la història medieval catalana com a temàtica literària».

17 TUBINO, Francisco M.: Historia del renacimiento literario contemporáneo en Cataluña, Baleares y Valencia, Madrid 1880, pp. 188-189. En 1835 había el proyecto de editar un Tesoro de la Lengua Catalana, presentado como un «monumento al idioma de nuestros padres», con los diccionarios cataláncastellano y el inverso, la gramática, los clasicos catalanes, biografias de catalanes ilustres y un repertorio bibliográfico de autores catalanes, con un total de 2.560 páginas, El Vapor, 20-III-1835.

18 FONTANA, Josep: «El romanticisme i la formació d'una histùria nacional catalana», El segle romàntic, Vilanova i la Geltrú 1997, p. 541.
}

Hispania, LXI/3, núm. 209 (2001) 907-932 
cia: «el quadre essencial dels fets que avui commemorem con a fites de la nacionalitat, incloent l'onze de setembre, no deriva de Pujades o de Capmany, sinó de Piferrer, que, en alguna manera, va ésser el primer a dibuixar les grans línies de la historia nacional de Catalunya» ${ }^{19}$. Retórica romántica, acompañada de buena información, empujaron a Piferrer a reivindicar con entusiasmo el pasado medieval catalán, a caballo entre la literatura y la historia. El apasionamiento por las grandezas medievales no se limitaba al aliento genérico de la obra, sino que se puede ejemplificar con citas. Piferrer recordaba «las felices épocas de los Raimundos y de los Jaimes», que los "Consejeros [de Ciento] fueron (...) el sostén de las libertades de su patria, que nunca consintieron fuesen holladas por mano de Rey o por corporación» o el «celo del Parlamento catalán por la conservación de los fueros que habían hecho la felicidad de sus mayores y que con tanta firmeza a principios del siglo pasado debían defender sus descendientes ${ }^{20} »$, en inequívoca referencia a la guerra de sucesión.

\section{ESPAÑA INARTICULADA: UN TESTIMONIO MADRILEÑO}

Desde los inicios del segundo tercio de siglo diversos publicistas catalanes de diferentes sectores ideológicos, reivindicaban la personalidad de Cataluña y de manera más solapada denunciaban la inarticulación de España ${ }^{21}$. Se podría pensar que esta percepción provenía de una toma de posición previa al análisis de la realidad, para sustentar propuestas descentralizadoras. Esta hipótesis se ve desmentida por un anónimo teórico posiblemente madrileño, o vinculado a los dirigentes estatales. En 1843 se publicó en Madrid, con un largo apéndice, la traducción de la obra de Louis Marie La Haye, vizconde de Cormenin, De la centralización. Cormenin (1788-1868), bonapartista radical en su juventud, realista con idéntico ímpetu en la restauración, panfletista antiorleanista a partir de 1830 , la preconizaba como la mejor alternativa político-administrativa ${ }^{22}$. Cormenin sostiene que la descentralización o el federalismo, que aparecen como sinónimos, favorecen el despotismo, tesis que el autor del apéndice quería demostrar con la historia española, a través de un sofismo: «nuestros Reyes, fuertes con la división, ojeriza, y aun rivalidad de los pueblos que, reunidos bajo su cetro, formaron la Monarquía llamada Española, pudieron a mansalva derribar el antiguo edificio Constitucional», primero Carlos V en Castilla, luego Felipe II en Aragón, y finalmente «Felipe V con ejércitos castellanos y fran-

19 FONTANA: «El romanticisme», p. 543. FraderA: Cultura, pp. 37-44 esp.

20 Piferrer, Pablo: Recuerdos y bellezas de España. Cataluña, I, Barcelona 1839, pp. 10, 14n y 95n.

21 Analizo con detalle la cuestión en ANGUERA: Els precedents...

${ }^{22}$ La obra se publicó con seudónimo, TIMON: De la centralización, traducida del francés, al cual se ha añadido un apéndice sobre los obstáculos que la opinión y las leyes oponen en España al principio de la centralización por D. R. S. y F. C., Madrid 1843. Cito per la edición de Barcelona 1844, donde el «Apéndice a la traduccion», ocupa las páginas 128-178.

Hispania, LXI/3, núm. 209 (2001) 907-932 
ceses», en Cataluña y Valencia. Los reyes, «solícitos en destruir hasta la menor seña de las antiguas libertades (...), evitaron cautelosamente igualar y amalgamar a los pueblos sujuzgados», imponiendo unas leyes y una lengua comunes, pero conservando vivas las «fuentes de división». La unidad española no cuajó hasta «la traidora invasión del año ocho», que vio como respuesta «renacer la adormecida nacionalidad Española, y (...) habría producido, por fin la suspirada unión (...) si la deplorable reacción de 1814, no hubiese agostado en flor tan patrióticas, y bien fundadas esperanzas ${ }^{23}$. Sus análisis, desde la perspectiva actual son a veces contradictorios, pero me interesa resaltarlos en la parte que ponen en evidencia la inarticulación de España, ya que ayudan a explicar el arraigo de los "provincialismos», entre ellos, y de manera destacada, el catalán y sus propuestas historiográficas.

Para el comentarista la libertad política tendía a la unidad (equiparada a la unificación) y el absolutismo promovía la fractura de la naciente construcción nacional. De acuerdo con su análisis formulaba afirmaciones que podían suscribir la mayoría de los analistas catalanes: con la restauración de Fernando VII «se conservó el sistema (...), de reputar á las provincias Castellanas como conquistadoras y dueñas, no como hermanas de las Aragonesas» ${ }^{24}$. Más aún, reconoce que en 1843 no existía una auténtica conciencia de ser español, ni en Cataluña ni en el resto de España. Para conseguirla era preciso «un gobierno Central, fuerte en lo esterior, y que tenga en lo interior la autoridad y poderío suficientes para proteger el interés general de la nación contra las ecsigencias del mezquino, y muchas veces deslumbrante interés provincial» ${ }^{25}$. Cerrando la argumentación sobre la necesidad de la centralización para construir España y garantizarle la libertad, admitía de nuevo la falta de conciencia colectiva de integrar una sola comunidad: «la Centralización (...) ha de crearse insensiblemente, y los pueblos de la antigua España han de fundirse por su propio impulso en un solo pueblo, antes que la ley, después de haberlo preparado con medios indirectos, sancione (...) y robustezca su mutuo y cordial enlace ${ }^{26}$. Para conseguir «la grande unidad nacional» proponía ocho medidas administrativas. Aquí conviene retener las que afectan a la necesidad de unificar los símbolos referenciales, para favorecer una identificación común. Era necesario, decía, disponer de «una enseña nacional», que aglutinara el sentimiento de españolidad, asumible por todos: «quédense entre los recuerdos históricos los Castillos y Leones al lado de las Barras Aragonesas, del Dragón de S. Jorge y de las Cadenas Navarras, o fórmese de todas ellas una sola divisa que simbolice su unión y enlace». En otras palabras, era imprescindible dotarse de un emblema único

23 Id. pp. 133-134.

${ }^{24}$ Id. p. 135. La idea de Cataluña tratada como provincia conquistada es recurrente en los publicistas catalanes del momento, entre otros ejemplos esta era la opinión de P. Mata en 1836, de F. Raull en 1835 o del general Prim en 1850, cfra. ANGUERA: Els precedents, pp. 126, 145 y 240.

25 Id. p. 137.

26 Id. p. 139.

Hispania, LXI/3, núm. 209 (2001) 907-932 
que hermanara a todos los territorios, no en vano «los Símbolos todo lo pueden con la mayoría de los hombres, y Símbolos de Nacionalidad son estos pendones, esos Escudos que sirven en todos los pueblos para conocerse, unirse y abrazarse los hijos de una común patria». Al denunciar la identificación gubernamental de España con Castilla, hacía una propuesta que en Cataluña nadie había osado formular:

«Por qué no ha de canviar ya el lenguaje oficial, que dejando a un lado la sucesión de los Reyes Aragoneses y Navarros la cuenta solo de los de León y Castilla? ¿por qué en el recinto de las Cortes Españolas solo han de verse los Leones y Castillos, dejando en olvido las Barras de Aragón y las Cadenas de Navarra (...)? ¿por qué no ha de haber empezado una nueva era, y con ella nueva sucesión de Reyes Españoles?»27.

Donde disentía totalmente de los publicistas catalanes era en la propuesta de una nueva división administrativa, mientras atacaba la provincial por haber respetado «con sobrada escrupulosidad los límites de la antigua» y proponía sin tapujos: «confúndanse en sus límites Cataluña con Aragón y Valencia, y estas con Castilla y Navarra, y a su vez ambas Castillas con Estremadura, Andalucía, Galicia y Provincias Vascongadas», para que los accidentes geográficos establecieran los límites y bautizaran las nuevas provincias según el modelo francés. El mismo esquema debería aplicarse a la jurisdicción eclesiástica, judicial y militar, pues «confundidos así unos con otros los dominios y reinos de la anterior monarquía, se olvidarían con facilidad los antiguos nombres, y no tardarían los Españoles en formar una grande familia, todos hermanos, todos hijos de una común madre» ${ }^{28}$. Como principales obstáculos a la unificación legal señalaba «la mala fe de muchos» y el «provincialismo mal entendido de los más». Aquí la propuesta da de nuevo un vuelco. La solución no pasaba por «la lucha entre las diferentes legislaciones (...) de los antiguos reinos», lo que parece una desautorización de la tendencia de aplicar en todas partes la legislación castellana, sino por un nuevo código, redactado por una comisión de expertos «en todos los que rigen en diferentes distritos» y los de "los mas ilustrados paises», en una propuesta de síntesis parecida a la que habían sugerido algunos diputados catalanes en Cádiz ${ }^{29}$. Así,

«adoptándose lo mejor de cada uno (...) se aplicarían tal vez á Cataluña, Aragón, Valencia y Navarra disposiciones útiles que contengan los códigos castella-

27 Id. pp. 143-145. En la p.143 reitera: «los pueblos diversos de la monarquia hasta ahora divididos, casi oficialmente y aun en el lenguaje vulgar, en dos clases imaginarias de conquistadores y conquistados».

${ }^{28}$ Id. pp. 145-147.

${ }^{29}$ ANGUERA: Els precedents, pp. 79-80. 
nos, y se importarían en cambio á las provincias de Castilla escelentes leyes y usos que, sin duda, abrazan los códigos de Aragón, Cataluña y Navarra»30.

La clave «mas decisiva para centralizar y fundir en uno los diversos pueblos, que juntos forman la Monarquía Española» era una enseñanza gratuita y uniforme de los cinco a los doce años, donde desaparece cualquier respeto a la diversidad cultural: no sólo el castellano sería la única lengua docente, sino que «los Maestros (...) habrían de hablar siempre á los niños en el bello idioma español, sin permitir a estos el uso de otro lenguage» ${ }^{31}$.

\section{EL PROGRESISMO: VÍCTOR BALAGUER Y LLUÍS CUTCHET}

El papel de Víctor Balaguer en la recuperación de la conciencia catalana es indiscutible. Narcís Oller rememorando sus años de juventud le presentaba como «aquell que, amb les seves fogoses poesies patriòtiques, i la seva novellesca i suggestiva Història de Catalunya fou qui més sabé encendre'ns (...) aquell sentiment de pàtria catalana que l'escarment cruelíssim del primer Borbó, havia aconseguit, si no apagar del tot, mantenir almenys estamordit encara en l'esperit dels nostres pares» ${ }^{32}$.

En 1858 Víctor Balaguer recopiló «unos lijeros estudios hijos de convicciones políticas profundamente arraigadas en mi corazón ${ }^{33}$, para establecer un vínculo entre las propuestas progresistas y la tradición histórica, centrándose en la libertad constitucional, ya que «la antigua Cataluña (...) ofrece al observador político un manantial inagotable (...) en sus glorias municipales y en sus costumbres constitucionales y parlamentarias (...) sobra de argumentos, tan lógicos como indestructibles, (...) en favor de mis ideas ${ }^{34}$ ". El libro es un ejercicio de redundancia en torno a estas ideas. Balaguer ponía a Cataluña como ejemplo de país con libertades históricas donde el despotismo era desconocido hasta que «llegó de Francia un ejército a imponernos un rey estranjero». Hasta entonces

${ }_{30}$ De la centralización, pp. 151-154.

${ }^{31}$ Id. pp. 154-158.

32 Oller, Narcís: Memùries literàries, a Obres Completes, II, Barcelona 1985, p. 717. En la p. 718 añade «els principis patriòtics que proclamava (...) ens tenien encisats i eren la llavor més fecunda que poc temps després havia de florir a l'ànima catalana de tot aquell jovent».

${ }^{33}$ La libertad constitucional. El epílogo está fechado el 28 de diciembre de 1857. La cita en la p. 7. Para más detalles sobre el papel de Balaguer en esta y otras etapas, ANGUERA: Els precedents, y FRADERA, Cultura, passim.

34 La libertad, p. 9. Cataluña era «tierra clásica de instituciones populares, en admirables franquicias municipales, en prácticas parlamentarias y en virtudes constitucionales», p. 218 . En la p. 13 afirma que quiere el libro útil para «nuestra nación y muy particularmente en Cataluña», donde nación es España.

Hispania, LXI/3, núm. 209 (2001) 907-932 
«teníamos reyes que reconocían públicamente los límites de su autoridad, y se envanecían de no tener las facultades omnímodas de otras soberanías (...). No es estraño, con reyes como estos y con instituciones como las antiquísimas nuestras, que Cataluña alcanzase el esplendor y brillo que patentiza la historia, perdiendolo todo el día que perdió su libertad»35.

Con evidente anacronismo, pero con pasión intensa, sostenía:

«puede decirse de los catalanes que su libertad civil y su libertad política nacieron con ellos, y admira y sorprende ver la constancia con que este pueblo ha guardado y defendido por espacio de tantos siglos sus instituciones constitucionales, venerándolas y conservándolas puras e intactas (...) ora de las demasías del poder, ora de los desenfrenos del populacho. Cataluña e Inglaterra se parecen en esto. Ninguna otra nación como ella ha sido tan firme y tan celosa defensora de su régimen constitucional, de su sistema parlamentario; ninguna otra nación puede, como Inglaterra, como Cataluña, presentar una serie mayor de sacrificios, de abnegaciones, de esfuerzos patrióticos hechos para sostener la libertad»36.

Para Balaguer, uniendo directamente la historia al momento en que escribía, «las Cortes catalanas proclamaron siempre como salvador el gran principio de la descentralización al que hoy se hace tan cruda guerra», siendo evidente que «muchas de las desgracias políticas de nuestra España contemporánea han provenido de no haber sabido comprender en verdadero espíritu nacional, que es en España una nacionalidad compuesta de diversas nacionalidades» al haberse inspirado los proyectos constitucionales en ejemplos extranjeros, despreciando las «admirables constituciones» propias que eran el modelo óptimo a seguir $^{37}$. El mejor modelo habría sido el catalán, lo que equivale a preconizar un esquema de espíritu federal. Para Balaguer ser catalán era sinónimo de defensor de la libertad y de las libertades. El resumen de su interpretación históricojurídica de Cataluña sería este: con la victoria de Felipe $\mathrm{V}$ «el ánjel de su independencia oculta el rostro entre sus alas y huye al cielo, perece su libertad, y entonces empieza a languidecer ${ }^{38}$. Era preciso despertarlo. Ocho años después, inspirándose en las luchas por la unificación italiana, afirmaba que «forman o deben formar una nacionalidad todos aquellos grupos que tienen una misma lengua, un mismo origen y la conciencia de lo que son», siendo éste el proyecto de futuro, «la doctrina de las nacionalidades es la única que puede encaminar a la humanidad por las vías de la paz, de la justicia y del progreso", y pasando de los conceptos generales al caso español defendía la aplicación de una estructura similar a la suiza o la de los EEUU, federal y a la vez unitaria, "como se enten-

\footnotetext{
${ }^{35}$ La libertad, pp. 33-34.

${ }^{36}$ La libertad, p. 120. En las, pp. 121-122, afirma que las cortes catalanas precedieron un siglo las castellanas y dos las inglesas.

37 La libertad, pp. 132 y $218-219$.

${ }^{38}$ La libertad, p. 240.
} 
día en la antigua Corona de Aragón, donde los estados eran varios, una la nación y el monarca uno» configurando «un modelo y un ejemplo de libertades y de federalismo con monarquía» ${ }^{39}$.

En 1860 publicó el primer volumen de la Historia de Cataluña y de la corona de Aragón. Las diferencias básicas con las historias nacionales europeas, a la sazón de moda son dos: mientras la mayoría narraban la historia de una nación-estado, Balaguer hacía la de un territorio sin estado; y, en segundo lugar, escribe una historia reivindicativa, dedicada esencialmente a sus coterráneos, en una lengua que no era la propia. Balaguer sumaba las palpitaciones románticas en la visión del pasado al afán de los progresistas por democratizar la estructura estatal, suma que se traducía en la voluntad de utilizar la historia como arma propagandística. Conciente de la función social de su obra, confesaba, ya en el subtítulo, los objetivos políticos y historiográficos que la justificaban: era una historia

«escrita para darla a conocer al pueblo, recondándole los grandes hechos de sus ascendientes en virtud, en patriotismo y armas, y para difundir entre todas las clases el amor al país y la memoria de sus glorias pasadas».

Si hasta entonces el pasado era «harto desconocido de los estraños por desgracia y harto poco conocido de los nuestros por malaventura», la situación estaba cambiando, pues «nunca había existido en Cataluña un anhelo tan vivo por conocer su historia, ni la juventud un deseo más ardiente por saber el pasado de este heroico país» ${ }^{40}$. Balaguer, a menudo acusado de precursor de la historiografía nacionalista catalana, si cae en algún ismo es precisamente en el español. «España por su posición geográfica señalada y por sus límites patentes parece incontestablemente destinada a contener un pueblo único, reunido en cuerpo de nación», pero con una salvedad democrática, «un pueblo único, sí, unido, pero confederado» porque «la centralización» equivalía a «la muerte política de España», que no se olvidaba de señalar era «un compuesto de diversas nacionalidades. Hoy son provincias lo que hace pocos siglos eran reinos y naciones ${ }^{41}$. Unidad/confederación, patria única/defensa de la personalidad de los territorios integrados en el estado, le empujaron a una semántica ambigua, que no impidió el patrocinio editorial de la obra por el ayuntamiento de Barcelona. Como tampoco impidió que los lectores descubrieran desde el primer momento que se había «impuesto la misión de desenterrar las glorias de su patria», y más aún que había tomado «sobre sus hombros la pesada carga de despertar el pasado de los catalanes desde los tiempos más remotos hasta nues-

39 BALAguen: Mis recuerdos de Italia, Barcelona 1890, pp. 367, 372 y 377. Los textos provienen de Anales de la guerra de Italia, Prusia y Austria, Barcelona 1866.

40 BALAguer: Historia de Cataluña y de la Corona de Aragón, Barcelona 1860, I, pp. 8-9. Vease los comentarios de SERRA, Eva: «Una aproximació a la historiografia catalana: els antecedents», Revista de Catalunya, 26 (1989), p. 38 y en general pp. 34-40.

41 BALAGUER: I, p. 12.

Hispania, LXI/3, núm. 209 (2001) 907-932 
tros días ${ }^{42}$. Tan evidente era el trasfondo de la obra, pese a que ahora no tiene porqué ser la lectura del todo coincidente, que fue objeto de la acusación que puede parecer inevitable: «el Sr. Balaguer (...) se deja llevar a veces con esceso del amor patrio» ${ }^{43}$.

Se hace necesario conocer el impacto de la historia en la sensibilidad popular, y su difusión real para poder valorar con precisión hasta qué punto contribuyó a difundir el conocimiento de la historia catalana, facilitando la incorporación de nuevos nombres al imaginario popular y a la consolidación de la conciencia de comunidad diferenciada. En este sentido la obra parece clave por la fecha de edición, por la agilidad narrativa y por la concesión a los gustos del público, al otorgar credibilidad y espacio a las leyendas. Ferran Soldevila, al tiempo que señalaba sus limitaciones, confirmó en 1925 las valoraciones que el propio Balaguer se atribuía en 1885: divulgó la historia de Cataluña, despertó el amor «a les coses de la terra», instigó a la investigación y difundió tradiciones, leyendas y anécdotas «que passaren a ser patrimoni de la joventut literaria», que las aprovechó en las composiciones poéticas. Para Soldevila, Balaguer fue el «historiador qui estimà Catalunya i qui va ensenyar a estimar-la a molts catalans", el iniciador de la "tradició ininterrompuda de preparació històrica, bona o dolenta, exacta o llegendària, que hom troba a les nostres classes populars, i que fa sovint d'un simple salta-taulells o viatjant de comerç un formidable polemista» ${ }^{44}$. El éxito de la Historia de Balaguer, dos ediciones y popularidad, no se repetió con la de Bofarull, más rigurosa, pero también más farragosa.

En 1858 Lluís Cutchet, amigo y correligionario político de Balaguer, publicó un estudio histórico ${ }^{45}$ que sustentaba las mismas tesis que este había defendido el mismo año en La libertad constitucional. Según Cutchet, «antes de la resurrección intelectual verificada en nuestros días (...), vagamente el pueblo (...) hablaba de grandeza pasada y de libertades perdidas» en los territorios de

42 Larrosa, G. A.: «Movimiento literario», Almanaque del Diario de Barcelona para el año 1862, Barcelona 1861, pp. 71-72. La Historia general de España de M. Lafuente se publicó de 1850 a 1867 en treinta volúmes, contemplando solo hasta la muerte de Fernando VII. J. M. Jover: La civilización española a mediados del s. XIX, Madrid 1991, alaba su valuntad constructora «de una conciencia nacional, entre muchas generaciones de españoles», p. 156. Una acertada crítica de la voluntad españolista con componentes castellanizadores de casi todas o todas las historias generales de España, vacías de la menor sensibilidad territorial en Pérez Garzón, J. Sisinio: La gestión de la memoria, Barcelona 2000, en especial pp. 63 y ss. Para TUBINO era «obra de intencionada propaganda», p. 358.

43 LARroSA: «Movimiento literario», Almanaque del Diario de Barcelona para el año 1864, Barcelona 1863 , p. 81 .

${ }_{44}$ Soldevila, Ferran: «La Histùria i l'Erudicció». El centenari de Víctor Balaguer», Revista de Catalunya, 7 (1925), vol. Il, pp. 59-61. Para FontANA, Josep: La fi de l'Antic Règim i la industrialització. 1787-1868, Barcelona 1988, p. 426, «va exercir una certa influència en la divulgació, però (...) no tenia ni rigor erudit ni cap mena de qualitat científica».

45 L. CUTCHET: Cataluña vindicada, [Barcelona 1858]. 
la antigua corona de Aragón ${ }^{46}$. Para él los catalanes habían sido «rebeldes al despotismo, es decir tenaces en la defensa de sus leyes» y «siempre prefirieron la libertad a la vida» ${ }^{47}$, actitud que mantenían viva. A lo largo del libro, quizá más que en La libertad constitucional de Balaguer, se intuye una clara conciencia catalana. El Compromiso de Caspe, casi siempre alabado como ejemplo de pactismo, fue una minoritaria «victoria radicalmente antinacional» ${ }^{48}$ y el destronamiento de Juan II «el mayor acto de sobiranía que pueda ejercer una nación», antes del despertar nacional provocado por Lutero o los «revolucionarios ingleses y franceses» ${ }^{49}$. En la misma linea argumental aseguraba que "los catalanes del siglo XV adoptaban y practicaban el principio de soberanía nacional como los castellanos de la misma época, entendiéndola ambos pueblos como la han entendido siempre los publicistas más elevados y los teólogos más eminentes» ${ }^{50}$. De manera más concreta, en Cataluña las «leyes políticas eran paccionadas» y «la obediencia a los reyes era siempre y muy legamente condicional», debiendo obedecerles tan solo cuando fuesen «la personificación más elevada del derecho» ${ }^{51}$. Cutchet hacía una calurosa defensa del catalán al que "ciertos embardunadores de papel niegan inocentemente el título de lengua», no en vano la lengua formaba parte fundamental del sentimiento nacional ${ }^{52}$.

Como los liberales del Trienio, elogiaba el palacio de la Generalitat como símbolo de las libertades: "esta casa es el alma del Principado, a la que los habitantes del mismo han tenido por costumbre defender con el mismo empeño que la vida» ${ }^{53}$. Y en la línea de Balaguer sostenía: «cuanto mas se estudia a los antiguos catalanes, mas parecidos se les encuentra, en cuanto á espíritu de gobierno, a los ingleses modernos ${ }^{54}$, haciendo a los catalanes unos precursores, no en vano «Cataluña (...) ya en el siglo XIII tenía su constitución política escrita pacto fundamental no muy extenso pero suficiente en un país de hombres, para contener a la corona en los límites convenientes» $\$ 5$.

\footnotetext{
${ }^{46}$ Cataluña, p. 8. Los testimonios recogidos en ANGUERA: Els precedents, passim, desmienten esta afirmación.

47 Cataluña, p. 10.

${ }^{48}$ Cataluña, p. 12. Esta tesis fue la sustentada por el catalanismo historiográfico posterior, p. e., DomèneCh MONTANer, Lluís: La iniquitat de Casp i la fi del Comtat d'Urgell, Barcelona 1930.

49 Cataluña, p. 72.

${ }^{50}$ Cataluña, p. 375.

${ }^{51}$ Cataluña, p. 376.

52 Cataluña, pp. 52-53.

53 Cataluña, p. 51 . La reivindicación del edificio de la Generalitat por su simbolismo durante el Trienio, ANGUERA: Els precedents, pp. 90-93.

${ }^{54}$ Cataluña, p. 80.

55 Cataliña, p. 377.

Hispania, LXI/3, núm. 209 (2001) 907-932
} 


\section{ANTONI DE BOFARULL Y EL RECUERDO REIVINDICATIVO DE LA NACIÓN CATA- LANA $^{56}$}

En ningún momento, a lo largo de su dilatada obra erudita y publicística, Antoni de Bofarull se planteó», a diferencia de Balaguer, una reivindicación política: le bastaba la manifestación del deseo cultural, con una etérea referencia esencialista. La terminología política del momento era más elíptica, aunque a la vez más grandilocuente que la actual y eran pocos los que se preocupaban de establecer una definición rigurosa de la terminología usada en sus escritos, lo que explica la polisemia de muchas palabras. Nación puede ser a la par o alternativamente España y Cataluña y la última, sin solución de continuidad, es denominada, a veces en el mismo texto, nación, región o provincia, sin que sea lícito establecer una caracterización de sentimientos a partir de este uso, ni enaltecedor, en el caso de nación, ni despreciativo en el de provincia. $\mathrm{Ni}$ a la inversa. En 1860, Bofarull sostenía, que «la homogeneidad consistía solo en la obediencia común a un solo poder, mas nunca en la igualdad de costumbres, leyes, idiomas, caracteres y hasta tendencias políticas ${ }^{57}$. La comunidad nacional era así definida indirectamente por tres elementos, que encontraban en la independencia política el camino máximo de desarrollo, la lengua, las costumbres y las leyes, complementados con un cuarto, presentado como el desencadenante del proceso histórico, el carácter, que moldeaba la ideología colectiva. La selección de elementos definidores le situaba dentro de la ortodoxia clásica de las definiciones de nación, de J. G. Fitchte a P. S. Mancini.

Como ha puesto de relieve Josep Fontana, Bofarull fue «conscient de la importància que la síntesi històrica tenía en aquesta reconstrucció cultural» ${ }^{58}$. A los treinta años formuló» una declaración de principios, que ayuda a entender el sentido de su dedicación profesional:

«cuando un país, por desgracia, deja de ser nación independiente y pasa tan solo a figurar confundido entre los estados de una gran monarquía, su preponderancia antigua queda olvidada por la que ejerce el estado dominante, su idioma de corte (...) pasa a ser vulgar en sus pueblos, sus usos y costumbres van desapareciendo (...) y hasta sus glorias y hazañas se oscurecen (...). Para el que conoce el valor del suelo que le vio nacer, solo queda, en consuelo, el estudio de las crónicas que se escribieron en los pasados siglos y, sobre todo, el entusiasmo que estas graban en el corazón del que lee»59.

56 Para más detalles mi artículo «La teoria nacional d'Antoni de Bofarull. Un exemple de la doble nacionalitat", en ANGUERA, Pere: Literatura, pàtria i societat. Els intelálectuals $i$ la nació, Vic 1999, p. p. 11-35.

57 "Introducción", p. VII, a Crónica catalana de Ramon Muntaner: texto original y traducción castellana, Barcelona 1860.

s8 La fi, p. 426.

59 Crónica del rey de Aragón D. Pedro IV, el Ceremonioso o del Punyalet [sic] escrita en lemosín por el mismo monarca, traducida al castellano y anotada, Barcelona 1850, «Introducción», p. V. FONTANA: La 
En su planteamiento la historia era fundamental para recuperar la conciencia nacional, "porque ella es el arsenal común que facilita armas así a los vencedores como a los vencidos» ${ }^{60}$.

De todas formas, a diferencia de Balaguer, Bofarull sólo en alguna ocasión insinúa una etérea propuesta de recuperación federativa, que se diluye entre la hipótesis y el canto al pasado. Elogiando a la monarquía federal catalanoaragonesa y su sistema de incorporación de territorios, afirmaba en 1860 que «sirvió constantemente para mantener en armonía todos los estados de Aragón, lo que no hubiera podido ser a quererles dar una violenta forma homogénea» ${ }^{61}$, con lo que parece indicar que una estructura similar sería la mejor solución para la España de su tiempo. Una lectura, quizá más apasionada, ofrecen unas frases escritas diez años antes. Según la introducción a la crónica del rey Ceremonioso, empezaba a "resentirse ya el ánimo» del historiador al comparar «lo que era y lo que es el país natal, y cuan grande es la desgracia de un pueblo que se agrega a otro, sino más vasto, más afortunado». Es evidente que parte del lamento, no todo necesariamente, provenía de la cuestión lingüística como lo demuestran las líneas siguientes, «si los estados de Aragón y Cataluña hubiesen continuado en su antigua importancia, si el idioma natural no se hubiese contaminado» con la desaparición de la corte, «si, en fin, después de un Fernando el Católico hubiese seguido un rey de Aragón y no un monarca de España», la crónica «no hubiese descansado olvidada en un rincón de archivo por tantos siglos» ${ }^{62}$. El lector tiene derecho a preguntarse si sólo para reivindicar una edición más temprana de la crónica hacía falta lamentarse del final de la dinastía propia. Quizá sí, porqué el mismo Bofarull concluye, pocas páginas después, «solo diré que mi ambición se cifra aquí, únicamente en propagar con la mejor buena fe y el más puro entusiasmo las glorias de nuestros mayores». Pero a pesar de todo añade, «con preferencia al mérito que pueda contraer para alcanzar un título académico. Hablo en esta ocasión como aragonés, pienso como catalán» ${ }^{63}$.

En 1855 en el artículo «Catalanismo no es provincialismo» se planteaba la hipótesis: «si la casualidad geográfica, en vez de colocar a Madrid en el centro, hubiese colocado una de nuestras capitales catalanas», y de acuerdo con el modelo político vigente en vez de castellanizar Cataluña se hubiese catalanizado España, las provincias castellanas

«no clamarían ahora con justicia, soltando llanto con patriótico fuego, cada vez que, buscando los timbres de su glorioso escudo, invocando el nombre de al-

\footnotetext{
$f i$, p. 426, que reproduce las primeras línias de la cita, ve en ellas «la nostàlgia de la independència». Para TUBINO: p. 258, Bofarull tradujo la crónica de Jaume I «guiado por sus patrióticas ideas».

60 «La lengua catalana considerada históricamente» [1857], cito por la reedición en Memorias de la Real Academia de Buenas Letras, II, Barcelona 1868, p. 316.

61 «Introducción», p. VIII, Crónica catalana de Ramon Muntaner.

62 «Introducción», p. VI a Crónica del rey don Pedro IV.

63. «Introducción» a Crónica del rey don Pedro, p. XVI.
} 
guno de sus muchos y respetables héroes, o alegando para guarecerse alguna de sus sabias leyes o sanas costumbres, toparan solo con las barras aragonesas»?

El buen provincialismo, el que debía sustentarse, era aquel que planteaba éstas, y sólo éstas, cuestiones, ya que «el conjunto de todas ellas es lo que más ha de contribuir a la formación de la auténtica gloria nacional» española ${ }^{64}$. La contraposición entre el proyecto cultural, catalán en su plenitud, y el político, español sin discusión, lo expuso de forma clara en 1854:

«no se ha de confundir el estado a que aspiramos, esto es el de la reaparición de nuestra literatura (...), de propagación de nuestra rica historia y de manifestación de nuestras envidiables glorias, con un capricho de emancipación mal entendido, y que no debe preocuparnos, como buenos españoles» 65 .

La renuncia de cualquier reivindicación política se contrapone con los cantos a la vocación nacional en el pasado. Al presentar, en 1860, la edición de la crónica de Ramon Muntaner, hacía referencia al «renacimiento de nuestro espíritu nacional, considerado, si se quiere, ahora, puramente bajo el carácter literario» ${ }^{66}$ del que era un ejemplo la reedición de la crónica. «Si se quiere», parece una concesión a la galería, a los lectores reticentes o los críticos, al tiempo que permite otras posibilidades menos neutras, que las estrictamente literarias, aunque no fueran las suyas, sino las de los que citaba en 1862, al referirse «al esfors del patriotisme (...) en colocar estatuas de passats héroes en certs punts de la ciutat» y comparaba las novelas históricas de tema catalán «al deliri que nostres escultors y pintors manifestan en reproduir fets y personatges de la història catalana pera tots sos treballs de geni» o a los poetas que cantaban "nostras olvidadas hassanyas» ${ }^{67}$ con una declarada voluntad de concienciar a los ciudadanos.

Bofarull es el autor de la segunda síntesis histórica, la Historia crítica (civil y eclesiástica) de Cataluña, cuya publicación se inició en 1876, en la que por primera vez Cataluña es la protagonista exclusiva de la narración. Con ella pretendía superar el romanticismo literario de Balaguer a través de una erudición positivista, traducida en un estilo árido, sin renunciar al talante reivindicativo. Como Balaguer navegaba entre dos sentimientos, el catalán y el español ${ }^{68}$ :

64 Diario de Barcelona, 30-I-1855, pp. 871-873. VICENS VIVES, J.: que lo atribuía a Duran y Bas, lo presentaba como "el punt de partida del regionalisme polític», Inustrials i polítics del segle XIX, Barcelona 1958, p. 270. Tubino, que no da el título, lo extracta y comenta con detalle y no duda en atribuirlo a Bofarull, pp. 300-301.

65 "Amor al país», reproducido por MIRACLE, J.: La restauració dels Jocs Florals, Barcelona 1960, p. 301.

66 «Introducción», p. XIII.

${ }^{67}$ La orfaneta de Menargues ó Catalunya agonisant, Barcelona 1862, p. 9. Una relación de las novelas en castellano de temática histórica catalana publicadas los años 50 y 60 en Barcelona, SERRAHIMA. M.; BOADA, M. T.: La novel la bistòrica en la literatura catalana, Barcelona 1996, pp. 31-32.

${ }^{68}$ SERRA: pp. $40-42$. 
«el país llamado Cataluña debe tener su representación en la historia que se llama general de aquella monarquía, y su importancia, bajo este punto de vista, es igual a la que pueda atribuirse cada región o nación de aquellas que fueron conocidas en diversos períodos y situaciones ${ }^{69}$.

Con estas propuestas no se alejaba demasiado de la interpretación básica formulada por Balaguer: Cataluña era parte integrante e inseparable de España. Según Vicens Vives, la historia de Bofarull «fou apassionadament llegida i analitzada por juristes i polítics de les noves promocions catalanes», mientras la de Balaguer, siguiendo Soldevila, «serví per a inspirar la corrua de poetes que aspiraren a l'englantina» ${ }^{70}$, lo que se puede sintetizar como una incidencia compensada, uno en los literatos, el otro en los teóricos. Bofarull, apologeta de la lengua y la historia, fue el intelectual que a lo largo de la segunda mitad del XIX más contribuyó a sentar las bases de una conciencia diferencial catalana (siempre dentro de España) construída simultaniamente a la aparición de la crisis de identidad de la clase dirigente que provoó la expansión de la industria, con las correspondientes tensiones sociales ${ }^{71}$. En definitiva un excelente ejemplo de la doble fidelidad nacional.

\section{HACIA LA SÍNTESIS DIVULGATIVA}

A finales del siglo XIX se dieron los pasos definitivos para que la síntesis histórica en clave nacionalista se popularizara y se pudiera leer en catalán. También que su extensión fuera más breve, para permitir una lectura popular amplia. En catalán y en un par de volúmenes se publicó la Història de Catalunya de Antoni Aulèstia Pijoan entre 1887 y 1889. Otras consideraciones, al margen de la lengua, establecen diferencias notables entre Aulèstia y Balaguer y Bofarull. Los dos últimos proclamaban su pesar por la escasa consideración de Cataluña en las historias generales de España, situando así sus obras en la categoría de historia regional, Aulèstia planteaba Cataluña como la unidad de análisis, el protagonista exclusivo. Militante significado y activo de la Associació Catalanista d'Excursions Científiques y de la Unió Catalanista ${ }^{72}$, veía su obra como un elemento didáctico enmarcado en la tarea de recuperación consciente de la personalidad catalana: «ponderant lo que teníam y lo que hem perdut, és com s'ha reanimat en las generacions actuals aqueix esperit (...) que tendeix a

69 BOFARULL: I, p. II.

70 VICENS VIVES: Industrials i politics, p. 201.

71 FRADERA: Cultura, pp. 125-126.

72 Para la Unió Catalanista Llorens, Jordi: La Unió Catalanista i els orígens del catalanisme politic, Montserrat1992, y ANGuerA, Pere: Escrits politics del segle XIX. Catalanisme cultural, Vic 1998, pp. 32-44, de la «Introducció» para la Associació Catalanista d'Excursions Científiques y su papel en la vertebración del catalanismo político.

Hispania, LXI/3, núm. 209 (2001) 907-932 
reintegrar a nostra terra en la plenitud de sos drets y de son cabal» ${ }^{73}$. En la misma introducción recordaba «la tendencia a tractar la historia baix lo punt de vista polítich-social, fentla entrar con a element d'estudi pera resoldrer lo gran problema del regionalisme», y que la historia tenía el deber de guiar al pueblo «en mitj de las contraposadas teorias que pretenen fer sa ditxa» ${ }^{4}$.

Su interpretación del pasado no se alejaba de la de Balaguer, más bien compartía la lectura de las épocas de esplendor, al sostener que la historia de Cataluña estaba presidida por el «principi de llibertad política» y «de la independencia y unitat de la nacionalitat catalana (...) y'l de la dignificació de la personalitat humana» ${ }^{75}$. Más aún, las reiteradas crisis españolas a lo largo del siglo XIX, con las abruptas substituciones en el poder de liberales y absolutistas y los frecuentes enfrentamientos armados, se debían a que ambas ideologías "partiren del principi unitarista antitétich al que informava la antiga constitució interna de la Monarquia» ${ }^{76}$. La de Aulèstia era la primera historia nacional de Cataluña y también la primera síntesis divulgadora ${ }^{77}$. Así lo reconocía Ernest Moliné en el prefacio de la segunda edición, en 1922: «sapigué incorporar al moviment catalanista (...) l'escola històrica catalana» ${ }^{78}$. No situaba las gestas catalanas en una historia española, sino que les otorgaba relevancia propia, aunque tampoco preconizaba propuestas independentistas para el nuevo diseño del estado. Un estado que debería ser más respetuoso con sus componentes y por ello, recordaba, había escrito su Historia en catalán, al ser «deber de tot amant de Catalunya contribuir en primer terme a propagar l'idioma propi» en aras del reconocimiento de «sos drets a la categoria de oficial»" esfuerzo de Aulèstia y de sus compañeros de generación lo parece confirmar un comentario periodístico de 1889: «ni uno sólo de nuestros paisanos, desconoce la herencia que la Historia ha legado á nuestra tierra» 80 .

Conseguida la posibilidad de divulgación entre los sectores con inquietudes culturales o patrióticas, faltaba el paso definitivo: facilitar la auténtica popularización del pasado catalán en los primeros estadios de la enseñanza, e, indirectamente, una fácil comprensión por las clases populares. La primera síntesis

\footnotetext{
73 Historia, I, p. VII. Entre 1877 y 1886, el núcleo de La Renaixensa, del cual Aulèstia formaba parte y que le editó la obra, publicó siete textos clásicos fundamentales. Véase el resumen de la actividad editorial en DuRAN, Carola: «L'estampa de la Renaixensa i Pere Aldavert», Actes del Col. loqui sobre Josep Yxart $i$ el seu temps, Tarragona 2000, p. 275.

${ }^{74}$ Historia, I, p. IX.

75 Historia, I, p. X.

${ }^{76}$ Historia, II, p. 535.

77 Una valoración en SERRA, ps. 42-45.

78 Vol. I, p. VII.

${ }^{79}$ Historia, I, p. XV. Para las primeras propuestas de reconocimiento del catalán, ANGUERA: El català, pp. 163-269.

80 GARrIGA, F. J.: «Algo de regionalismo», El Barcelonés, 6-VI-1889, citado por Domingo, Josep M.: "Sobre la crítica de literatura catalana em El Barcelonés (1884-1890). Notes», Actes Yxart, p. 318.
} 
escolar se debe a Norbert Font y Saguè, dedicado entonces en cuerpo y alma a la propaganda nacionalista. Font publicó en 1899, a los veinticinco años, su Història de Catalunya. El libro, que alcanzó la cuarta edición en 1933, está dedicado a Eusebi Güell, «fundador de la primera escola catalana». Para Font el conocimiento y el papel de la historia eran claves en el desarrollo del espíritu nacional:

«si volguessim esbrinar els factors més importants que han intervingut en la reivindicació de la Nacionalitat Catalana (...), sens dubte trobaríem que, més que els desencerts i vexacions del Centralisme, han estat els estudis històrics. Aquests són els fonaments sobre els quals descansen els carreus del nostre programa».

La constatación era bien explícita: «la historia patria és un dels medis indicats i pràctics por ajudar al desvetllament d'un poble» ${ }^{81}$.

Para Font la obra de Aulèstia, meritoria y destacable, era aún demasiado extensa. Su propósito era nítido: ofrecer «un llibre de propaganda que tant pogués servir al noi que ha acabat les beceroles, com per al jaiet de noranta anys; que fos tan assequible a l'obrer que amb feines toca mai un llibre, com a 1 'home de carrera», en definitiva «un llibre d'ensenyament por a xics i grans». Font, reputado geólogo y sacerdote en ejercicio, tenía una idea clara de las necesidades y las responsabilidades de cara a los futuros lectores. No quería «enumerar un sense fi de guerres, batalles, noms i dates» que sólo servían para «carregar la memoria de l'estudiant, sense donar-li cap idea del que ha estat la Nació», por el contrario lo que hacía falta era facilitar al lector «l'estat de la nostra Pàtria en les diferents èpoques històriques, conèixer el desenrotllament de les nostres arts i ciències, les causes $i$ efectes dels successos històrics, i l'enllaç d'aquests successos» ${ }^{82}$, en definitiva un planteamiento extraordinariamente moderno. El compendio se abre con la prehistoria y termina con una referencia a la Exposición Universal de 1888. Asimismo conviene recordar que las dos terceras partes (pp. 39-124) estan dedicadas al periodo comprendido desde la entrada de los árabes a la muerte de Fernando II, mientras el siglo XIX es liquidado en nueve páginas, al contrario de la mayoría de síntesis actuales que concentran las épocas medieval y moderna y se detienen en la contemporánea.

\footnotetext{
81 FONT i SAGUÈ: Norbert, Histùria de Catalunya, p. 7, cito por la edición de 1933.

82 FONT: p. 9 . A la p. 10 informa «havem seguit un mètode especial, molt usat a l'estranger, que s'emmotlla a les intel. ligències més curtes». Inmediatamente reconoce, "no havem escrit una obra d'erudicció, sinó de propaganda». En el prólogo a la segunda edición (1907), asegura que había «estat adoptada de text en algunes escoles», ed. 1933, p. 13.
} 


\section{LoS JUEgos FLORALES DE BARCELONA ${ }^{83}$}

La información suministrada por las diversas historias surtió argumentos y anécdotas para construir discursos políticos e ideológicos. La historia recordaba grandezas pasadas, hechos heroicos, libertades políticas abolidas o, entre otras cosas, la existencia de una personalidad pública reconocida. Una plataforma compartida por los diversos grupos del catalanismo cultural y político fueron los Jocs Florals donde, al lado de poemas más o menos ripiosos pero siempre muy al gusto de la época, los discursos rituales del presidente del consistorio, del secretario del jurado y de uno de los mantenedores constituían a menudo declaraciones programáticas, no sólo literarias. Por este motivo la fiesta anual tuvo un importante papel en la vertebración del catalanismo, paralelo al que los poemas premiados ejercieron en la construcción de los mitos catalanistas, asociando la reivindicación política, con numerosas referencias historicistas, al resurgir literario. Este papel fue ya señalado por sus protagonistas, no en vano Víctor Balaguer al efectuar un balance de los Jocs en 1868, afirmaba que «digas en contra lo que's vulla, la moderna literatura catalana es la espressió del sentiment vivament despertat d'una gran nacionalitat y d'una llibertat perdudas», aunque matizando, "y, al mateix temps, l'esperansa de temps millors en una restauració de nacionalitat ibérica», uniendo en una sola las esperanzas renovadoras para Cataluña y España. Balaguer se mostraba contundente al presentar los Jocs como una «consecuencia legítima y lògica del despertament històrich, polítich y literari de Catalunya» ${ }^{84}$.

Desde el primer momento los impulsores del certamen quisieron darle una representación que ultrapasara la fiesta poética, valorando los componentes de recuperación del pasado y de propuesta de futuro. Las palabras iniciales de la memoria de Antoni de Bofarull como secretario del primer consistorio en 1859 lo manifiestan de manera sintética: «no hi ha poble sobre la terra que, pera enrobustir lo que se diu son present, no haja mirat sempre á dos punts extrems y cardinals, dels cuals reb ell la vida: al passat, y al futur: de allí ahont ve: allá ahont vá» ${ }^{55}$. Dos años más tarde, Lluís G. de Pons justificaba la presencia en la fiesta de un público numeroso y variopinto, porque gente de todos los estamentos había oido «aquella mateixa veu (...): no deixis morir la lengua, si vols que visca la patria; honra ton bressol, y honrarás ta bandera». Que hable de

\footnotetext{
83 Para la historia y la evolución de los Jocs Floral, TASIS MARCA, Rafael: Els Jocs Florals de Barcelona en l'evolució del pensament de Catalunya (1859-1958), Barcelona 1997. El proceso de recuperación en MIRACLE, Josep: La restauració dels Jocs Florals, Barcelona 1960. Una síntesis interpretativa en JORBA, Manuel: «Els Jocs Florals», a RIQUER/COMAS/MOLAS, Histùria de la literatura catalana, 7 , Barcelona 1986, pp. 123-151.

${ }^{84}$ BALAGUER, Víctor: Esperansas y recorts, ps. 77-78. JORBA, p. 133, insinua «la capacitat de proposta programàtica dels discursos i de certs textos literaris», p. 133, presentando algunos poemas como «autèntics discursos reivindicatius», p. 139. Con menor contundencia MIRACLE: pp. 57-58.

85 Jochs Florals de Barcelona en 1859, p. 29.
} 
una patria, Cataluña, y de una bandera, la catalana, no debe llamar a engaño, ni menos buscar fantasmas secesionistas, ya que immediatamente aparecía el refente español como justificación última de los Jocs, en un contexto donde no deja duda alguna de que la nación es España, «fes gran a la província, y faràs a la nació més gloriosa» ${ }^{86}$. La misma dualidad proclamaba en 1866 Pau Valls, un abogado de ascendencia carlista: «serian Catalunya y sos fills uns mals patricis lo día que reneguessin dels seus llars» pero "consemtim espontáneament y fins ab gust que Espanya tinga una sola existencia, una sola fe y un sol Rey» ${ }^{87}$.

Otros ejemplos confirman la dualidad de fidelidades y sentimientos. Si en 1876 Enric Claudi Girbal era taxativo al manifestar que «Catalunya serà sempre per a sos naturals la vera pàtria», a renglón seguido añadía que «sos fills defensaran com un sol home la integritat fins a pérdrer la última gota de sanch de sas venas» como lo hizo en el «Bruch y Girona», donde las dudas sobre el sujeto de la integridad las desvanecen los ejemplos de nítida beligerancia española ${ }^{88}$. El mismo año Lluís Cutchet en la glosa del lema del certamen (Fides, Patria, Amor) se arriesgaba a definir el concepto de patria,

«per patria no s'ha d'enténdrer solament la part geográfica, lo territori, petit o gran, que una rassa o nació habita; sino encara l'idioma, las institucions, lleys y costums, las creèncias y las tradicions, en una paraula, tots los elements més importants de la continuitat d'una comuna existència; formantse de tot això unit l'Història (...) de gent d'una mateixa sang, entenentse naturalment que eixa Història ha de ser mirall reproduhint l'imatge de la anterior vida nacional».

La conclusión era el pie de igualdad con que Cataluña podía mirar a «las nacions més insignes» a partir de una historia que mostraba como «Catalunya és sempre lo baluart més ferm d'Espanya», como se puso en evidencia durante la guerra napoleónica ${ }^{89}$. Cutchet quiso resaltar que podían coexistir una dualidad de sentimentos, uno, histórico-cultural, catalán y otro, político, español. Para «no donar lloch a ilusions» recordaba la irreversibilidad de la situación política: «créurer avuy necessari lo complert restabliment d'antigas institucions que (...) tenian en son temps natural rahó de ser, fora absurditat, y encara iniquitat evidenta». Para dar fuerza a su afirmación utilizaba un sofismo: en los tiempos antiguos frente a unas pocas ciudades con regímenes «quasi democratitsats» la mayoría de los pueblos se hallaban sometidos a la jurisdicción nobiliaria «mes dura que la de'ls nostres reys" y de la administración local saltaba a la generalización: «l'amor á aquellas institucions y practicas és lógich y és legítim (...), pero la resurrecció d'aquell complicat organisme no seria ara sensata,

${ }^{86}$ Jochs Florals... 1861, «Discurs», p. 30.

${ }^{87}$ Jochs Florals... 1866, «Discurs», p. 20.

${ }^{88}$ Jochs Florals... 1876, «Discurs de gracias», p. 335.

${ }^{89}$ Jochs Florals... 1876, «Discurs», p. 34.

Hispania, LXI/3, núm. 209 (2001) 907-932 
ni és possible», por lo que de «las vellas institucions cathalanas (...) hi ha que aténdrer al fondo, a la substancia ans que a la forma» ${ }^{90}$.

La historia, en cambio, servía a Josep Lluís Pons y Gallarza para demostrar que Cataluña era la patria y «aqueixa pàtria no es una ficció del nostre temps: ben senyalada la deixà lo rey Jaume I rallant ab la punta de sa espasa les ones de la mar desde Salou fins a Mallorca y de Mallorca fins a les salzeredes del Turia. La pàtria catalana fou, és y serà un fet històrich, y la germandat entre sos fills un parentiu que no s'esborra» ${ }^{91}$. Pons daba un consejo a los impulsores del catalanismo emergente «recordéuvos que l'esperit novell de la terra ha d'ésser fill de l'esperit antich y que l'antich y'l novell no poden ésser sinó un mateix esperit» ${ }^{92}$. En sintonía similar Manuel Duran y Bas presentaba la historia como un elemento básico en la recuperación de la conciencia nacional: «iay dels pobles que (...) buscan lo tipo de perfecció fora de la historia, de las condicións, dels interesos de cada nació, és a dir, de tot allò que la individualisa, y lluytan ufanosos per la importació de lleys, de parla, d'institucions, de costums de forastera terra»93.

A menudo los discursos denunciaron la castellanización, no sólo lingüística, de la sociedad catalana lo que equivalía a su desnaturalitzación. La pérdida de los referentes evidenciaba el envilecimiento del país. La denuncia contra la castellanitzación y el intento de confundir el espíritu del estado y sus símbolos con los de Castilla no era obstáculo, pese a su reiteración, para una también reiterada declaración de fidelidad española, aunque siempre con una aureola de catalanidad, que tenía su epicentro en la defensa de la lengua ${ }^{94}$. El 1874 Albert de Quintana lo expresaba con frases ditirámbicas:

"plena de glòria mes gran que la passada, més honesta, més ferma y duradera, la nova Catalunya fa visita a Castella (...), y allí admirada y respectada de tots, la vençuda per les armes, vencedora pel giny y la força del treball, crida ab veu més forta que les tremontanes: «visca, ique visca Espanya!...» mes ho diu en catalá»95.

En un tono similar Enric Claudi Girbal identificaba Cataluña como «la vera pàtria», para sostener inmediatamente la indisolubilidad de España. Era dentro de España donde debían marcarse los elementos diferenciales: «la terra catalana, dintre de la gran nacionalitat espanyola, conservarà sempre sa fesomia

\footnotetext{
90 Jochs Florals... 1876, «Discurs», p. 41.

${ }_{91}$ Jochs Florals... 1878, «Discurs", p. 33.

92 Jochs Florals... 1878, «Discurs», p. 36.

93 Jobcs Florals... 1885, «Discurs», p. 34.

94 Como recuerda JORBA, p. 129, «les protestes d'espanyolisme (...) responien a una inquietud que posa de manifest la repercussió de la institució». Según MIRACLE: p. 252, para evitar problemas se hacía «indispensable una confessió d'espanyolitat».

95 Jocs Florals... 1874, «Discurs», pp. 36-37.
} 
pròpia, sas costums peculiars, sos sentiments especials y sobre tot sa llengua» ${ }^{96}$. España era la «agrupació» de la germandat ibèrica» y el estadio superior de la comunidad, como españolas eran los glorias catalanas por ser «la patria general» a quién en la hora de la verdad «cap poble d'aquesta Península ha sigut en realitat mes fiel» que el catalán ${ }^{97}$. Pons y Gallarza, después de cantar el pasado y de augurar el futuro de la nacionalidad catalana, daba un giro al discurso para llegar a la conclusión "iquéns mancarà jamay per fernos lloch entre tots los fills de nostra Espanya?»98. Para Frederic Soler si «lo catalanisme en los fills de Catalunya es un efecte tan lógich com lo castellanisme en los fills de Castella», ambos debían cooperar para dar vida y honor a una España con convivencia cívica, sin hostilidades ni afanes de dominio internos, no en vano su aspiración era «véurer la mèva pátria [Espanya] poderosa y rica daurada (...) per los raigs de glòria de ma estimada Catalunya»99. Mantener el carácter y «nostras grans institucións jurídicas y literarias (...) dintre de la noble nació espanyola de la que tením a llegítim ergull ser membres» era el deseo expresado por Manuel Duran y Bas ${ }^{100}$.

Una cierta disidencia la marcó el republicano Gonçal Serraclara, quién empujado por el «desfogament patriótich», quería «recordar los meus», haciendo una importante precisión: "no precisament a tots los espanyols a qui com germans hem de estimar, sinó particular y esclusivament als catalans entre'ls qui he nascut, he viscut y vull morir» ${ }^{101}$. Como disonante era el federal Josep M. Vallès y Ribot, quién después de preconitzar la solidaridad con los otros territorios históricos despojados de sus antiguos privilegios, terminaba su discurso

«fent vots (...) perque lo renaixement catalanista (...) arribi prompte a fortificar completament la personalitat de Catalunya, reivindicant per la nostra terra tot lo que li correspon. iDeu no permeti que en aquesta noble tasca trobi en son camí cap Inglaterra! Però si contra nostres desitjos y nostres esforsos aixís desgraciadament sucseheix y Catalunya's trobés en situació consemblant a la de Irlanda iDéu vulga, allavors, que tinga un Parnell, com tingué en 1640 un Pau Clarís!»102,

en una velada amenaza de enfrentamiento armado, aunque condicionada a que la actuación gubernamental rompiera el respeto mútuo. En un sentido parecido, se expresaba Joan Permanyer y Ayats en 1891. Después de repasar la evolución del pensamiento catalán, sostenía que la recuperación catalana aún

\footnotetext{
96 Jochs Florals... 1876, «Discurs de gracias», p. 335.

97 Jochs Florals... 1876, «Discurs», pp. 34-35.

98 Jochs Florals... 1878, «Discurs», p. 36-37.

99 Jochs Florals... 1882, «Discurs», pp. 30 i 34.

100 Jochs Florals... 1884, «Discurs», p. 41.

101 Jochs Florals... 1879, «Discurs», p. 35.

102 Jobcs Florals... 1885, «Discurs de gracias», pp. 295-296.
}

Hispania, LXI/3, núm. 209 (2001) 907-932 
no había finalizado, en lo que puede leerse como manifestación de una voluntad que iba més allá de la pura descentralización:

«lo que'ns falta es poder llegir en lo llibre del porvenir escrit per la má de Deu si vindrá per vía natural y pacífica ó ab estremituts convulsivas lo dia que s'acosta. Tancats dins lo límits de las imperfectas facultats humanas, consolemnos, donchs, sabent que l'hora de la llibertat es arribada, que prompte los cataláns tornarém á tenir Pátria y que Catalunya de nou deixará escritas ab lletras d'or novas gestas gloriosas en lo llibre de la Historia»103.

${ }^{103}$ Jochs Florals...1891, «Discurs», pp. 53-55 y 58. 